\title{
Teknik Penentuan Solusi Sistem Persamaan Diferensial Linear Non-Homogen Orde Satu
}

\author{
Technical to Find The System of Linear Non-Homogen \\ Differential Equation of First Order
}

\author{
Ahmad Nurul Hadi", Eddy Djauhari, Asep K. Supriatna, Muhamad Deni Johansyah \\ Departemen Matematika, FMIPA, Universitas Padjadjaran \\ *ahmadnurulhadi99king@gmail.com
}

\begin{abstract}
Abstrak. Penentuan solusi sistem persamaan diferensial linear non-homogen orde satu dengan koefisien konstanta, dilakukan dengan mengubah sistem persamaan tersebut menjadi persamaan diferensial linear non homogen tunggal. Dari persamaan diferensial linear non homogen tunggal tersebut kemudian dicari solusi homogennya menggunakan akar-akar karakteristiknya, dan mencari solusi partikularnya dengan metode variasi parameter. Solusi umum dari persamaan diferensial linear tersebut adalah jumlah dari solusi homogen dan solusi partikularnya. Persamaan diferensial linear tunggal tersebut berorde- $n$, yang solusi umumnya berbentuk $x_{n}$. Selanjutnya dicari solusi umum berebentuk $x_{n-1}$ yang berkaitan dengan $x_{n}$, solusi umum berbentuk $x_{n-2}$ yang berkaitan dengan $x_{n}$ dan $x_{n-1}$, solusi umum berbentuk $x_{n-3}$ yang berkaitan dengan $x_{n}, x_{n-1}$, dan $x_{n-2}$, demikian seterusnya sampai mencari solusi umum berbentuk $x_{1}$ yang berkaitan dengan $x_{n}, x_{n-1}, x_{n-2}$, $x_{n-3}, \ldots, x_{2}$. Kumpulan solusi umum yang berbentuk $x_{n}, x_{n-1}, x_{n-2}, \ldots, x_{1}$ merupakan solusi umum dari sistem persamaan diferensial linear non homogen orde satu tersebut.
\end{abstract}

Kata kunci: Diferensial, Linear, Non-Homogen, Orde, Satu.

\begin{abstract}
Determination of first-order non-homogeneous linear differential equation system solutions with constant coefficients, carried out by changing the system of equations into a single non-homogeneous linear differential equation. From a single non-homogeneous differential equation, a homogeneous solution is then used using its characteristic roots, and looking for a particular solution with the parameter variation method. The general solution of these linear differential equations is the number of homogeneous solutions and their particular solutions. The single linear differential equation is n-order, the solution being in the form of $x_{n}$. Then look for a general solution in the form of $x_{(n-1)}$ related to $x_{n}$, a general solution in the form of $x_{(n-2)}$ related to $x_{n}$ and $x_{(n-1)}$, general solutions in the form of $x_{(n-3)}$ related to $x_{n}, x_{(n-1)}$, and $x_{(n-2)}$, and so on until looking for a general solution in the form of $\mathrm{x}_{1}$ related to $x_{n}, x_{(n-1)}, x_{(n-2)}, x_{(n-3)}, \ldots, x_{2}$. A collection of general solutions in the form of $x_{n}, x_{(n-1)}$, $x_{(n-2)}, \ldots, x_{1}$ is the general solution of the first-order non-homogeneous linear differential equation system.
\end{abstract}

Keywords: Linear, Differential, First, Order, Non-Homogeneous

\section{Pendahuluan}

Banyak permasalahan dalam bidang lain seperti bidang sains, teknik, ekonomi bahkan bidang bisnis yang dapat diformulasikan secara matematis membentuk suatu persamaan diferensial. Persamaan diferensial adalah persamaan yang memuat atau melibatkan turunan (derivative) atau diferensial dari fungsi yang tidak diketahui. Selain permasalahan yang melibatkan persamaan diferensial, banyak pula permasalahan yang melibatkan sistem dari persamaan diferensial. Salah satunya adalah sistem yang melibatkan persamaan diferensial linear orde satu. Ada beragam metode yang bisa digunakan dalam menentukan sistem persamaan diferensial linear, diantaranya adalah metode nilai eigen dan metode operator diferensial.

Dalam karya tulis ini, akan disajikan cara menentukan solusi sistem persamaan diferensial linear non homogen orde satu dengan koefisien konstanta, yaitu dengan mengonstruksi sistem persamaan 
tersebut menjadi persamaan diferensial linear tunggal orde- $n$. Kemudian dari persamaan tersebut akan dicari solusi homogen dengan menggunakan akar-akar karakteristiknya, selanjutnya mencari solusi partikularnya dengan metode variasi parameter. Jumlah dari solusi homogen dan solusi partikularnya adalah solusi umum dari persamaan diferensial linear tunggal orde- $n$ tersebut. Setelah itu akan dicari persamaan lain yang membentuk sistem persamaan diferensial linear orde satu tersebut

\section{Metode Penelitian}

Pada bagian ini dijelaskan mengenai langkah-langkah dalam menentukan solusi sistem persamaan diferensial linear non homogen orde satu. Berikut langkah-langkahnya :

a. Mengonstruksi sistem persamaan diferensial linear non homogen orde satu dengan koefisien konstanta menjadi persamaan diferensial linear tunggal atau persamaan diferensial biasa.

b. Mencari solusi homogen dari persamaan diferensial tersebut dengan menggunakan akar-akar karakteristiknya.

c. Mencari solusi partikular dari persamaan diferensial tersebut dengan menggunakan metode variasi parameter.

d. Menentukan solusi umum dari persamaan diferensial linear tunggal tersebut yaitu menjumlahkan solusi homogen dan solusi partikularnya.

e. Menentukan solusi dari persamaan-persamaan lain yang membentuk sistem persamaan diferensial linear non homogen tersebut.

\section{Hasil dan Pembahasan}

Diberikan sistem persamaan diferensial linear non homogen orde satu dengan $n$ persamaan dan $n$ fungsi yang tidak diketahui, sebagai berikut

$$
\begin{aligned}
& x_{1}^{\prime}=a_{11} x_{1}+a_{12} x_{2}+a_{13} x_{3}+\cdots+a_{1 n} x_{n}+f_{1}(t) \\
& x_{2}^{\prime}=a_{21} x_{1}+a_{22} x_{2}+a_{23} x_{3}+\cdots+a_{2 n} x_{n}+f_{2}(t) \\
& x_{3}^{\prime}=a_{31} x_{1}+a_{32} x_{2}+a_{33} x_{3}+\cdots+a_{3 n} x_{n}+f_{3}(t) \\
& x_{n-1}^{\prime}=a_{(n-1) 1} x_{1}+a_{(n-1) 2} x_{2}+a_{(n-1) 3} x_{3}+\cdots+a_{(n-1) n} x_{n}+f_{n-1}(\mathrm{t}) \\
& x_{n}^{\prime}=a_{n 1} x_{1}+a_{n 2} x_{2}+a_{n 3} x_{3}+\cdots+a_{n n} x_{n}+f_{n}(t)
\end{aligned}
$$

dengan $a_{i j}$ adalah koefisien konstanta atau fungsi konstan untuk $i, j=1,2,3, \ldots, n$ dan $f_{j}(t)$ adalah fungsi yang dapat diturunkan, untuk $j=1,2,3, \ldots, n$.

Jika solusi pertama yang akan dicari adalah persamaan $x_{n}^{\prime}$, maka persamaan $x_{n}^{\prime}$ diturunkan satu kali terhadap $t$, diperoleh

$$
x_{n}^{\prime \prime}=a_{n 1} x_{1}^{\prime}+a_{n 2} x_{2}^{\prime}+a_{n 3} x_{3}^{\prime}+\cdots+a_{n n} x_{n}^{\prime}+f_{n}^{\prime}(t)
$$

dari (1) diketahui bahwa

$$
\begin{array}{rcccccc}
x_{1}^{\prime} & =a_{11} x_{1} & +a_{12} x_{2} & +a_{13} x_{3} & +\cdots+a_{1 n} x_{n} & +f_{1}(t) \\
x_{2}^{\prime} & =a_{21} x_{1} & +a_{22} x_{2} & +a_{23} x_{3} & +\cdots+a_{2 n} x_{n} & +f_{2}(t) \\
x_{3}^{\prime} & =a_{31} x_{1} & +a_{32} x_{2} & +a_{33} x_{3} & +\cdots+a_{3 n} x_{n} & +f_{3}(t) \\
\vdots & \vdots & \vdots & \vdots & \ddots & \vdots & \vdots \\
x_{(n-1)}^{\prime} & = & a_{(n-1) 1} x_{1} & +a_{(n-1) 2} x_{2} & +a_{(n-1) 3} x_{3} & +\cdots+a_{(n-1) n} x_{n} & +f_{(n-1)}(t) .
\end{array}
$$


Selanjutnya dengan mensubstitusikan persamaan (3) ke persamaan (2) didapat

$$
\begin{aligned}
x_{n}^{\prime \prime}= & \sum_{i_{1}=1}^{n-1} a_{n i_{1}} a_{i_{1} 1} x_{1}+\sum_{i_{1}=1}^{n-1} a_{n i_{1}} a_{i_{1} 2} x_{2}+\sum_{i_{1}=1}^{n-1} a_{n i_{1}} a_{i_{1} 3} x_{3}+\cdots+ \\
& \sum_{i_{1}=1}^{n-1} a_{n i_{1}} a_{i_{1} n} x_{n}+\sum_{i_{1}=1}^{n-1} a_{n i_{1}} f_{i_{1}}(t)+a_{n n} x_{n}^{\prime}+f_{n}^{\prime}(t) .
\end{aligned}
$$

Misalkan

$$
\begin{aligned}
& C_{1_{1}}=\sum_{i_{1}=1}^{n-1} a_{n i_{1}} a_{i_{1} 1}, \quad C_{1_{2}}=\sum_{i_{1}=1}^{n-1} a_{n i_{1}} a_{i_{1} 2}, \quad C_{1_{3}}=\sum_{i_{1}=1}^{n-1} a_{n i_{1}} a_{i_{1} 3}, \ldots, \quad C_{1_{n}}=\sum_{i_{1}=1}^{n-1} a_{n i_{1}} a_{i_{1} n} \\
& f_{1_{1}}(t)=\sum_{i_{1}=1}^{n-1} a_{n i_{1}} f_{i_{1}}(t)+f_{n}^{\prime}(t) .
\end{aligned}
$$

Sehingga persamaan (4) dituliskan menjadi

$$
x_{n}^{\prime \prime}=C_{1_{1}} x_{1}+C_{1_{2}} x_{2}+C_{1_{3}} x_{3}+\cdots+C_{1_{n}} x_{n}+a_{n n} x_{n}^{\prime}+f_{1_{1}}(t) .
$$

Berdasarkan persamaan (1) dapat diketahui bahwa

$$
x_{1}=\frac{x_{n}^{\prime}-a_{n 2} x_{2}-a_{n 3} x_{3}-\cdots-a_{n n} x_{n}-f_{n}(t)}{a_{n 1}},
$$

dengan mensubstitusikan persamaan (6) ke persamaan (5) didapat

$$
\begin{aligned}
x_{n}^{\prime \prime}= & \left(C_{1_{2}}-\frac{C_{1_{1}} a_{n 2}}{a_{n 1}}\right) x_{2}+\left(C_{1_{3}}-\frac{C_{1_{1}} a_{n 3}}{a_{n 1}}\right) x_{3}+\cdots+\left(C_{1_{n}}-\frac{C_{1_{1}} a_{n n}}{a_{n 1}}\right) x_{n}+ \\
& \left(a_{n n}+\frac{C_{1_{1}}}{a_{n 1}}\right) x_{n}^{\prime}+f_{1_{1}}(t)-\frac{C_{1_{1}}}{a_{n 1}} f_{n}(t) .
\end{aligned}
$$

Misalkan

$$
\begin{aligned}
& C_{2_{2}}=\left(C_{1_{2}}-\frac{C_{1_{1}} a_{n 2}}{a_{n 1}}\right), \quad C_{2_{3}}=\left(C_{1_{3}}-\frac{C_{1_{1}} a_{n 3}}{a_{n 1}}\right), \ldots, \quad C_{2_{n}}=\left(C_{1_{n}}-\frac{C_{1_{1}} a_{n n}}{a_{n 1}}\right) \\
& C_{k_{1}}=\left(a_{n n}+\frac{C_{1_{1}}}{a_{n 1}}\right), \quad f_{1_{2}}(t)=f_{1_{1}}(t)-\frac{C_{1_{1}}}{a_{n 1}} f_{n}(t) .
\end{aligned}
$$

Persamaan (7) dituliskan menjadi 


$$
x_{n}^{\prime \prime}=C_{2_{2}} x_{2}+C_{2_{3}} x_{3}+\cdots+C_{2(n-1)} x_{n-1}+C_{2_{n}} x_{n}+C_{k_{1}} x_{n}^{\prime}+f_{1_{2}}(t) .
$$

Persamaan (8) diturunkan satu kali terhadap $t$, menjadi

$$
x_{n}^{\prime \prime \prime}=C_{2_{2}} x_{2}^{\prime}+C_{2_{3}} x_{3}^{\prime}+\cdots+C_{2(n-1)} x_{n-1}^{\prime}+C_{2_{n}} x_{n}^{\prime}+C_{k_{1}} x_{n}^{\prime \prime}+f_{1_{2}}^{\prime}(t) .
$$

Berdasarkan (1) diketahui bahwa

$$
\begin{aligned}
& x_{2}^{\prime}=a_{21} x_{1}+a_{22} x_{2}+a_{23} x_{3}+\cdots+a_{2 n} x_{n} \quad+f_{2}(t) \\
& x_{3}^{\prime}=a_{31} x_{1}+a_{32} x_{2}+a_{33} x_{3}+\cdots+a_{3 n} x_{n}+f_{3}(t)
\end{aligned}
$$

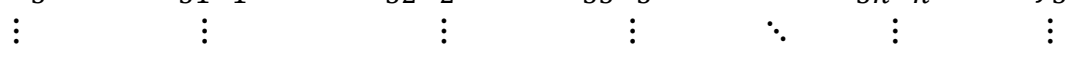

$$
\begin{aligned}
& x_{(n-1)}^{\prime}=a_{(n-1) 1} x_{1}+a_{(n-1) 2} x_{2}+a_{(n-1) 3} x_{3}+\cdots+a_{(n-1) n} x_{n}+f_{(n-1)}(t) \text {, }
\end{aligned}
$$

dengan mensubstitusikan persamaan (10) ke (9) didapat

$$
\begin{aligned}
x_{n}^{\prime \prime \prime}= & \sum_{i_{2}=2}^{n-1} C_{2_{i_{2}}} a_{i_{2} 1} x_{1}+\sum_{i_{2}=2}^{n-1} C_{2 i_{2}} a_{i_{2} 2} x_{2}+\sum_{i_{2}=2}^{n-1} C_{2_{i_{2}}} a_{i_{2} 3} x_{3}+\cdots+ \\
& \sum_{i_{2}=2}^{n-1} C_{2 i_{2}} a_{i_{2} n} x_{n}+C_{2_{n}} x_{n}^{\prime}+C_{k_{1}} x_{n}^{\prime \prime}+f_{1_{2}}^{\prime}(t)+\sum_{i_{2}=2}^{n-1} C_{2 i_{2}} f_{i_{2}}(t)
\end{aligned}
$$

Misalkan

$$
\begin{aligned}
& C_{3_{1}}=\sum_{i_{2}=2}^{n-1} C_{2 i_{2}} a_{i_{2} 1}, \quad C_{3_{2}}=\sum_{i_{2}=2}^{n-1} C_{2 i_{2}} a_{i_{2} 2}, \quad C_{3_{3}}=\sum_{i_{2}=2}^{n-1} C_{2 i_{2}} a_{i_{2} 3}, \ldots, \\
& C_{3_{n}}=\sum_{i_{2}=2}^{n-1} C_{2 i_{2}} a_{i_{2} n}, \quad f_{1_{3}}(t)=f_{1_{2}}^{\prime}(t)+\sum_{i_{2}=2}^{n-1} C_{2 i_{2}} f_{i_{2}}(t) .
\end{aligned}
$$

Persamaan (11) dituliskan menjadi

$$
x_{n}^{\prime \prime \prime}=C_{3_{1}} x_{1}+C_{3_{2}} x_{2}+C_{3_{3}} x_{3}+\cdots+C_{3_{n}} x_{n}+C_{2_{n}} x_{n}^{\prime}+C_{k_{1}} x_{n}^{\prime \prime}+f_{1_{3}}(t),
$$

dengan mensubstituikan persamaan (6) ke persamaan (12) didapat

$$
\begin{aligned}
x_{n}^{\prime \prime \prime}= & \left(C_{3_{2}}-\frac{C_{3_{1}} a_{n 2}}{a_{n 1}}\right) x_{2}+\left(C_{3_{3}}-\frac{C_{3_{1}} a_{n 3}}{a_{n 1}}\right) x_{3}+\cdots+\left(C_{3_{n}}-\frac{C_{3_{1}} a_{n n}}{a_{n 1}}\right) x_{n}+ \\
& \left(C_{2_{n}}+\frac{C_{3_{1}}}{a_{n 1}}\right) x_{n}^{\prime}+C_{k_{1}} x_{n}^{\prime \prime}+f_{1_{3}}(t)-\frac{C_{3_{1}}}{a_{n 1}} f_{n}(t) .
\end{aligned}
$$


Misalkan

$$
\begin{aligned}
& C_{4_{2}}=\left(C_{3_{2}}-\frac{C_{3_{1}} a_{n 2}}{a_{n 1}}\right), \quad C_{4_{3}}=\left(C_{3_{3}}-\frac{C_{3_{1}} a_{n 3}}{a_{n 1}}\right), \ldots, \quad C_{4_{n}}=\left(C_{3_{n}}-\frac{C_{3_{1}} a_{n n}}{a_{n 1}}\right), \\
& C_{k_{2}}=\left(C_{2_{n}}+\frac{C_{3_{1}}}{a_{n 1}}\right), \quad f_{1_{4}}(t)=f_{1_{3}}(t)-\frac{C_{3_{1}}}{a_{n 1}} f_{n}(t) .
\end{aligned}
$$

Persamaan (13) dituliskan menjadi

$$
x_{n}^{\prime \prime \prime}=C_{4_{2}} x_{2}+C_{4_{3}} x_{3}+\cdots+C_{4_{n}} x_{n}+C_{k_{2}} x_{n}^{\prime}+C_{k_{1}} x_{n}^{\prime \prime}+f_{1_{4}}(t)
$$

Berdasarkan persamaan (8) dapat diketahui bahwa

$$
x_{2}=\frac{x_{n}^{\prime \prime}-C_{2_{3}} x_{3}-\cdots-C_{2_{n}} x_{n}-C_{k_{1}} x_{n}^{\prime}-f_{1_{2}}(t)}{C_{2_{2}}},
$$

dengan mensubsitusikan persamaan (15) ke persamaan (14) didapat

$$
\begin{aligned}
x_{n}^{\prime \prime \prime}= & \left(C_{4_{3}}-\frac{C_{4_{2}} C_{2_{3}}}{C_{2_{2}}}\right) x_{3}+\left(C_{4_{4}}-\frac{C_{4_{2}} C_{2_{4}}}{C_{2_{2}}}\right) x_{4}+\cdots+\left(C_{4_{n}}-\frac{C_{4_{2}} C_{2_{n}}}{C_{2_{2}}}\right) x_{n}+ \\
& \left(C_{k_{2}}-\frac{C_{4_{2}} C_{k_{1}}}{C_{2_{2}}}\right) x_{n}^{\prime}+\left(C_{k_{1}}+\frac{C_{4_{2}}}{C_{2_{2}}}\right) x_{n}^{\prime \prime}+f_{1_{4}}(t)-\frac{C_{4_{2}}}{C_{2_{2}}} f_{1_{2}}(t) .
\end{aligned}
$$

Misalkan

$$
\begin{gathered}
C_{5_{3}}=\left(C_{4_{3}}-\frac{C_{4_{2}} C_{2_{3}}}{C_{2_{2}}}\right), \quad C_{5_{4}}=\left(C_{4_{4}}-\frac{C_{4_{2}} C_{2_{4}}}{C_{2_{2}}}\right), \ldots, \quad C_{5_{n}}=\left(C_{4_{n}}-\frac{C_{4_{2}} C_{2_{n}}}{C_{2_{2}}}\right), \\
C_{k_{3}}=\left(C_{k_{2}}-\frac{C_{4_{2}} C_{k_{1}}}{C_{2_{2}}}\right), \quad C_{k_{4}}=\left(C_{k_{1}}+\frac{C_{4_{2}}}{C_{2_{2}}}\right), \quad f_{1_{5}}(t)=f_{1_{4}}(t)-\frac{C_{4_{2}}}{C_{2_{2}}} f_{1_{2}}(t),
\end{gathered}
$$

sehingga persamaan (16) dituliskan menjadi

$$
x_{n}^{\prime \prime \prime}=C_{5_{3}} x_{3}+C_{5_{4}} x_{4}+\cdots+C_{5(n-1)} x_{n-1}+C_{5_{n}} x_{n}+C_{k_{3}} x_{n}^{\prime}+C_{k_{4}} x_{n}^{\prime \prime}+f_{1_{5}}(t) .
$$

Jika persamaan $x_{n}^{\prime \prime \prime}$ diturunkan satu kali lagi terhadap $t$, maka akan diperoleh persamaan $x_{n}^{(4)}$, nilai-nilai yang dapat disubstitusikan ke persamaan $x_{n}^{(4)}$ adalah $x_{3}^{\prime}, x_{4}^{\prime}, x_{5}^{\prime}, \ldots x_{n-1}^{\prime}$ dan $x_{1}, x_{2}, x_{3}$. Jika penurunan dari persamaan $x_{n}^{\prime}$ terhadap $t$ dilakukan hingga $(n-1)$ kali, maka akan diperoleh persamaan $x_{n}^{(n)}$, nilainilai yang dapat disubstitusikan ke persamaan $x_{n}^{(n)}$ adalah $x_{n-1}^{\prime}$ dan $x_{1}, x_{2}, x_{3}, \ldots, x_{n-2}$. Sehingga persamaan $x_{n}^{(n)}$ dapat dituliskan dalam bentuk persamaan diferensial linear tunggal oerde- $n$, yaitu :

$$
x_{n}^{(n)}=C_{j_{i}} x_{n}+C_{k_{p_{1}}} x_{n}^{\prime}+C_{k_{p_{2}}} x_{n}^{\prime \prime}+C_{k_{p_{3}}} x_{n}^{\prime \prime \prime}+\cdots+C_{k_{p_{n-1}}} x_{n}^{(n-1)}+f_{1_{q}}(t)
$$


dengan $C_{j_{i}}, C_{k_{p_{1}}}, C_{k_{p_{2}}}, C_{k_{p_{3}}}, \ldots, C_{k_{p_{n}}}$ adalah konstanta dan $f_{1_{q}}(t)$ adalah fungsi. Bentuk persamaan (18) dapat dituliskan menjadi

$$
x_{n}^{(n)}-C_{k_{p_{n-1}}} x_{n}^{(n-1)}-\cdots-C_{k_{p_{3}}} x_{n}^{\prime \prime \prime}-C_{k_{p_{2}}} x_{n}^{\prime \prime}-C_{k_{p_{1}}} x_{n}^{\prime}-C_{j_{i}} x_{n}=f_{1_{q}}(t) .
$$

Akan dicari solusi homogen untuk persamaan (19), persamaan (19) dituliskan menjadi

$$
x_{n}^{(n)}-C_{k_{p_{n-1}}} x_{n}^{(n-1)}-\cdots-C_{k_{p_{3}}} x_{n}^{\prime \prime \prime}-C_{k_{p_{2}}} x_{n}^{\prime \prime}-C_{k_{p_{1}}} x_{n}^{\prime}-C_{j_{i}} x_{n}=0
$$

Solusi dari bentuk persamaan diferensial tersebut yaitu:

Misalkan $x_{n}=e^{\lambda t}, x_{n}^{\prime}=\lambda e^{\lambda t}, x_{n}^{\prime \prime}=\lambda^{2} e^{\lambda t}, x_{n}^{\prime \prime \prime}=\lambda^{3} e^{\lambda t}, \ldots, x_{n}^{(n)}=\lambda^{n} e^{\lambda t}$

Kemudian dengan mensubstitusikan pemisalan di atas ke dalam persamaan (20) diperoleh

$$
\begin{aligned}
& \lambda^{n} e^{\lambda t}-C_{k_{p_{n-1}}} \lambda^{n-1} e^{\lambda t}-\cdots-C_{k_{p_{3}}} \lambda^{3} e^{\lambda t}-C_{k_{p_{2}}} \lambda^{2} e^{\lambda t}-C_{k_{p_{1}}} \lambda e^{\lambda t}-C_{j_{i}} e^{\lambda t}=0 \\
& e^{\lambda t}\left(\lambda^{n}-C_{k_{p_{n-1}}} \lambda^{n-1}-\cdots-C_{k_{p_{3}}} \lambda^{3}-C_{k_{p_{2}}} \lambda^{2}-C_{k_{p_{1}}} \lambda-C_{j_{i}}\right)=0
\end{aligned}
$$

Nilai dari $e^{\lambda t}$ tidak mungkin sama dengan nol, berarti

$$
\lambda^{n}-C_{k_{p_{n-1}}} \lambda^{n-1}-\cdots-C_{k_{p_{3}}} \lambda^{3}-C_{k_{p_{2}}} \lambda^{2}-C_{k_{p_{1}}} \lambda-C_{j_{i}}=0 .
$$

Cara menentukan solusi persamaan diferensial di atas yaitu :

1. Jika akar-akar karakteristik yang diperoleh real dan berbeda $\left(\lambda_{1} \neq \lambda_{2} \neq \lambda_{3} \neq \cdots \neq \lambda_{n}\right)$, maka solusi dari (20) adalah

$$
x_{n} h(t)=c_{1} e^{\lambda_{1} t}+c_{2} e^{\lambda_{2} t}+c_{3} e^{\lambda_{3} t}+\cdots+c_{n} e^{\lambda_{n} t}
$$

2. Jika akar-akar karakteristik yang diperoleh real dan sama $\left(\lambda_{1}=\lambda_{2}=\lambda_{3}=\cdots=\lambda_{n}\right)$, maka solusi dari (20) adalah

$$
x_{n} h(t)=\left(c_{1}+c_{2} t+c_{3} t^{2}+\cdots+c_{n} t^{n-1}\right) e^{\lambda t} .
$$

3. Jika akar-akar karakteristik yang diperoleh kompleks sekawan tidak berulang $\left(\lambda_{i j}=\alpha \pm \beta\right)$ maka solusi dari (20) yang memuat akar kompleks sekawan adalah

$$
x_{n} h(t)=c_{1} e^{\alpha t} \cos \beta t+c_{2} e^{\alpha t} \sin \beta t .
$$

4. Jika akar-akar yang diperoleh kompleks sekawan berulang $\left(\lambda_{12}=\lambda_{34}=\alpha \pm \beta\right)$ maka solusi dari (20) yang memuat akar kompleks sekawan berulang adalah

$$
x_{n} h(t)=c_{1} e^{\alpha t} \cos \beta t+c_{2} e^{\alpha t} \sin \beta t+c_{3} t e^{\alpha t} \cos \beta t+c_{4} t e^{\alpha t} \sin \beta t .
$$

Selanjutnya akan dicari solusi partikular untuk persamaan (19). Misal solusi homogen untuk persamaan (19) adalah

$$
\begin{aligned}
& x_{n} h(t)=c_{1} e^{\lambda_{1} t}+c_{2} e^{\lambda_{2} t}+c_{3} e^{\lambda_{3} t}+\cdots+c_{n} e^{\lambda_{n} t} \\
& x_{n} h(t)=c_{1} x_{n 1}+c_{2} x_{n 2}+c_{3} x_{n 3}+\cdots+c_{n} x_{n n} .
\end{aligned}
$$


Menurut metode variasi parameter, penyelesaian partikular $x_{n} p(t)$ diberikan

$$
x_{n} p(t)=u_{1}(t) x_{n 1}(t)+u_{2}(t) x_{n 2}(t)+u_{3}(t) x_{n 3}(t)+\cdots+u_{n}(t) x_{n n}(t)
$$

dalam hal ini $u_{1}(t), u_{2}(t), u_{3}(t), \ldots, u_{n}(t)$ harus ditentukan sehingga dapat memenuhi persamaan (19), yang diperoleh dari

$$
\left[\begin{array}{ccrll}
x_{n 1} & x_{n 2} & x_{n 3} & \cdots & x_{n n} \\
x_{n 1}^{\prime} & x_{n 2}^{\prime} & x_{n 3}^{\prime} & \cdots & x_{n n}^{\prime} \\
x_{n 1}^{\prime \prime} & x_{n 2}^{\prime \prime} & x_{n 3}^{\prime \prime} & \cdots & x_{n n}^{\prime \prime} \\
\vdots & \vdots & \vdots & \ddots & \vdots \\
x_{n 1}^{(n-1)} & x_{n 2}^{(n-1)} & x_{n 3}^{(n-1)} & \cdots & x_{n n}^{(n-1)}
\end{array}\right]\left[\begin{array}{c}
u_{1}^{\prime} \\
u_{2}^{\prime} \\
u_{3}^{\prime} \\
\vdots \\
u_{n}^{\prime}
\end{array}\right]=\left[\begin{array}{c}
0 \\
0 \\
0 \\
\vdots \\
f_{1_{q}}(t)
\end{array}\right]
$$

karena $x_{n 1}, x_{n 2}, x_{n 3}, \ldots, x_{n n}$ adalah solusi bebas linear untuk persamaan $x_{n}^{(n)}-C_{k_{p_{n-1}}} x_{n}^{(n-1)}-\cdots-$ $C_{k_{p_{3}}} x_{n}^{\prime \prime \prime}-C_{k_{p_{2}}} x_{n}^{\prime \prime}-C_{k_{p_{1}}} x_{n}^{\prime}-C_{j_{i}} x_{n}=0$, maka Wronskian-nya adalah tak nol. Bentuk Wronskiannya dapat ditulis sebagai

$$
W(t)=W\left(x_{1}, x_{2}, x_{3}, \ldots, x_{n}\right)=\left|\begin{array}{ccccc}
x_{n 1} & x_{n 2} & x_{n 3} & \cdots & x_{n n} \\
x_{n 1}^{\prime} & x_{n 2}^{\prime} & x_{n 3}^{\prime} & \cdots & x_{n n}^{\prime} \\
x_{n 1}^{\prime \prime} & x_{n 2}^{\prime \prime} & x_{n 3}^{\prime \prime} & \cdots & x_{n n}^{\prime \prime} \\
\vdots & \vdots & \vdots & \ddots & \vdots \\
x_{n 1}^{(n-1)} & x_{n 2}^{(n-1)} & x_{n 3}^{(n-1)} & \cdots & x_{n n}^{(n-1)}
\end{array}\right|
$$

Sehingga dapat ditentukan solusi untuk $u_{1}^{\prime}, u_{2}^{\prime}, u_{3}^{\prime}, \ldots, u_{n}^{\prime}$, dengan menggunakan metode Cramer yaitu

$$
u_{m}^{\prime}(t)=\frac{f_{1_{q}}(t) W_{m}(t)}{W(t)}
$$

dengan $m=1,2,3, \ldots n$ dan $W_{m}(t)$ adalah determinan yang diperoleh dengan mengganti kolom ke- $m$ dari $W(t)$ dengan $(0,0,0, \ldots, 1)$.Sehingga

$$
u_{m}(t)=\int \frac{f_{1_{q}}(t) W_{m}(t)}{W(t)} d t
$$

karena $x_{n} p(t)=u_{1}(t) x_{n 1}(t)+u_{2}(t) x_{n 2}(t)+u_{3}(t) x_{n 3}(t)+\cdots+u_{n}(t) x_{n n}(t)$ maka

$$
x_{n} p(t)=\sum_{m=1}^{n} u_{m}(t) \cdot x_{n m}(t) .
$$

Sehingga solusi umum dari persamaan (19) adalah

$$
\begin{aligned}
& x_{n}(t)=x_{n} h(t)+x_{n} p(t) \\
& x_{n}(t)=c_{1} x_{n 1}+c_{2} x_{n 2}+c_{3} x_{n 3}+\cdots+c_{n} x_{n n}+\sum_{m=1}^{n} u_{m}(t) \cdot x_{n m}(t) .
\end{aligned}
$$

Selanjutnya adalah menentukan solusi untuk $x_{1}, x_{2}, x_{3}, \ldots, x_{n-1}$. Misal yang akan dicari adalah solusi untuk $x_{2}$, maka yang perlu dilakukan adalah melakukan operasi terhadap persamaan (15), untuk 
mencari solusi $x_{1}$ maka harus dilakukan operasi terhadap persamaan (6). Begitupun untuk mencari solusi yang lainnya.

\section{Contoh 3.1}

Diberikan sistem persamaan diferensial sebagai berikut

$$
\begin{aligned}
& x_{1}^{\prime}(t)=\frac{1}{10^{3}} x_{3}(t)-\frac{1}{10^{3}} x_{1}(t)+\frac{125}{10^{3}} \\
& x_{2}^{\prime}(t)=\frac{1}{10^{3}} x_{1}(t)-\frac{1}{10^{3}} x_{2}(t)+\frac{125}{10^{4}} \\
& x_{3}^{\prime}(t)=\frac{1}{10^{3}} x_{2}(t)-\frac{1}{10^{3}} x_{3}(t)-\frac{125}{10^{4}}
\end{aligned}
$$

Sistem persamaan di atas dibagi menjadi tiga persamaan yaitu

$$
\begin{aligned}
& x_{1}^{\prime}=\frac{1}{10^{3}} x_{3}-\frac{1}{10^{3}} x_{1}+\frac{125}{10^{3}} \\
& x_{2}^{\prime}=\frac{1}{10^{3}} x_{1}-\frac{1}{10^{3}} x_{2}+\frac{125}{10^{4}} \\
& x_{3}^{\prime}=\frac{1}{10^{3}} x_{2}-\frac{1}{10^{3}} x_{3}-\frac{125}{10^{4}}
\end{aligned}
$$

Jika solusi pertama yang akan dicari adalah persamaan (24), maka persamaan (24) diturunkan satu kali terhadap $t$, diperoleh

$$
x_{3}^{\prime \prime}=\frac{1}{10^{3}} x_{2}^{\prime}-\frac{1}{10^{3}} x_{3}^{\prime}
$$

Selanjutnya dengan mengikuti langkah-langkah yang dimulai dari persamaan (3) sampai persamaan (18) akan diperoleh

$$
x_{3}^{\prime \prime \prime}+\frac{3}{10^{3}} x_{3}^{\prime \prime}+\frac{3}{10^{6}} x_{3}^{\prime}=\frac{125}{10^{9}}
$$

Selanjutnya dicari solusi homogen untuk persamaan (26), dengan persamaan karakteristik persamaan (26) dinyatakan sebagai

$$
\lambda^{3}+\frac{3}{10^{3}} \lambda^{2}+\frac{3}{10^{6}} \lambda=0
$$

Dengan memfaktorkan persamaan (27) didapat akar-akar karakteristiknya yaitu

$$
\lambda=0, \lambda=\frac{-3+\sqrt{3} i}{2000}, \lambda=\frac{-3-\sqrt{3} i}{2000} .
$$

Sehingga solusi homogen untuk persamaan (26) adalah

$$
x_{3} h(t)=C_{1}+C_{2} e^{-\frac{3}{2000} t} \sin \frac{\sqrt{3}}{2000} t+C_{3} e^{-\frac{3}{2000} t} \cos \frac{\sqrt{3}}{2000} t
$$


Selanjutnya akan dicari solusi partikular untuk persamaan (26) dengan metode variasi parameter, dari persamaan (28) diperoleh

$$
x_{31}=1, \quad x_{32}=e^{-\frac{3}{2000} t} \sin \frac{\sqrt{3}}{2000} t, \quad x_{33}=e^{-\frac{3}{2000} t} \cos \frac{\sqrt{3}}{2000} t,
$$

sehingga Wronskiannya adalah

$$
W(t)=\left|\begin{array}{lll}
x_{31} & x_{32} & x_{33} \\
x_{31}^{\prime} & x_{32}^{\prime} & x_{33}^{\prime} \\
x_{31}^{\prime \prime} & x_{32}^{\prime \prime} & x_{33}^{\prime \prime}
\end{array}\right|
$$

$W(t)=$

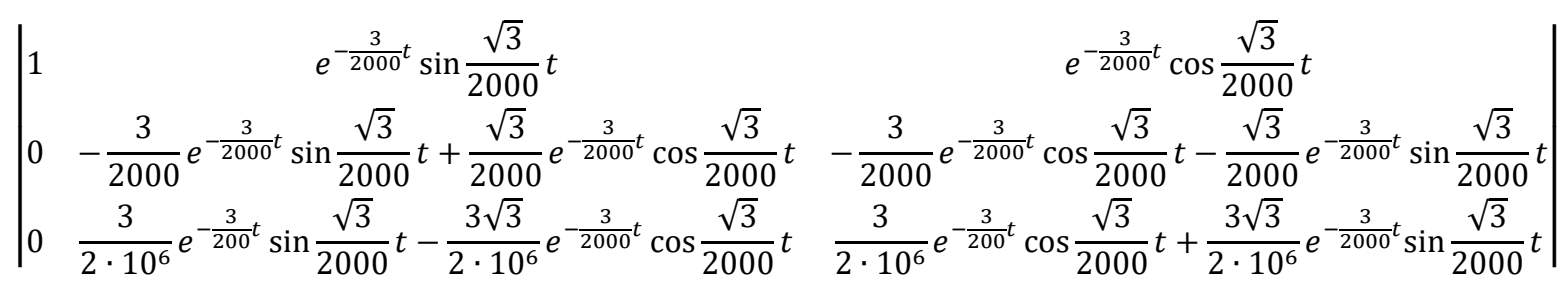

$$
\begin{aligned}
& W(t)=-\frac{3 \sqrt{3}}{2 \cdot 10^{9}} e^{-\frac{6}{2000} t},
\end{aligned}
$$

selanjutnya dicari nilai-nilai $W_{1}(t), W_{2}(t)$, dan $W_{3}(t)$

$$
W_{1}(t)=\left|\begin{array}{lll}
0 & x_{32} & x_{33} \\
0 & x_{32}^{\prime} & x_{33}^{\prime} \\
1 & x_{32}^{\prime \prime} & x_{33}^{\prime \prime}
\end{array}\right|
$$

$W_{1}(t)=$

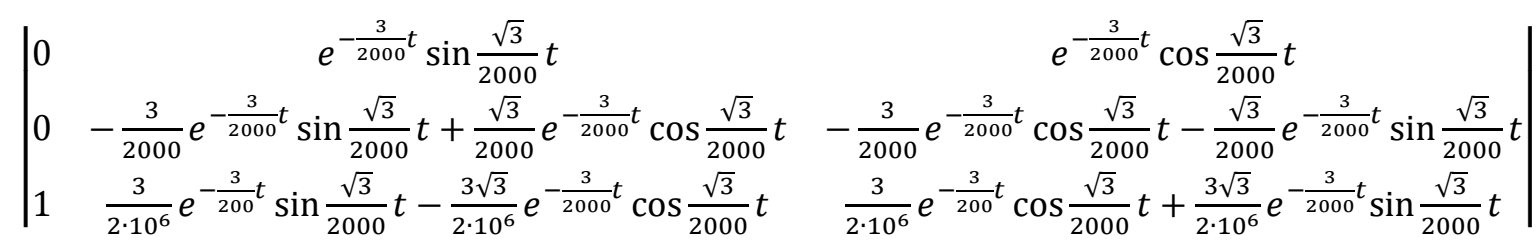

$$
\begin{aligned}
& W_{1}(t)=-\frac{\sqrt{3}}{2000} e^{-\frac{6}{2000} t} \\
& W_{2}(t)=\left|\begin{array}{lll}
x_{31} & 0 & x_{33} \\
x_{31}^{\prime} & 0 & x_{33}^{\prime} \\
x_{31}^{\prime \prime} & 1 & x_{33}^{\prime \prime}
\end{array}\right|
\end{aligned}
$$




$$
\begin{aligned}
& W_{2}(t)=\left|\begin{array}{ccc}
1 & 0 & e^{-\frac{3}{2000} t} \cos \frac{\sqrt{3}}{2000} t \\
0 & 0 & -\frac{3}{2000} e^{-\frac{3}{2000} t} \cos \frac{\sqrt{3}}{2000} t-\frac{\sqrt{3}}{2000} e^{-\frac{3}{2000} t} \sin \frac{\sqrt{3}}{2000} t \\
0 & 1 & \frac{3}{2 \cdot 10^{6}} e^{-\frac{3}{200} t} \cos \frac{\sqrt{3}}{2000} t+\frac{3 \sqrt{3}}{2 \cdot 10^{6}} e^{-\frac{3}{2000} t} \sin \frac{\sqrt{3}}{2000} t
\end{array}\right| \\
& W_{2}(t)=\frac{3}{2000} e^{-\frac{3}{2000} t} \cos \frac{\sqrt{3}}{2000} t+\frac{\sqrt{3}}{2000} e^{-\frac{3}{2000} t} \sin \frac{\sqrt{3}}{2000} t \\
& W_{3}(t)=\left|\begin{array}{lll}
x_{31} & x_{32} & 0 \\
x_{31}^{\prime} & x_{32}^{\prime} & 0 \\
x_{31}^{\prime \prime} & x_{32}^{\prime \prime} & 1
\end{array}\right|
\end{aligned}
$$

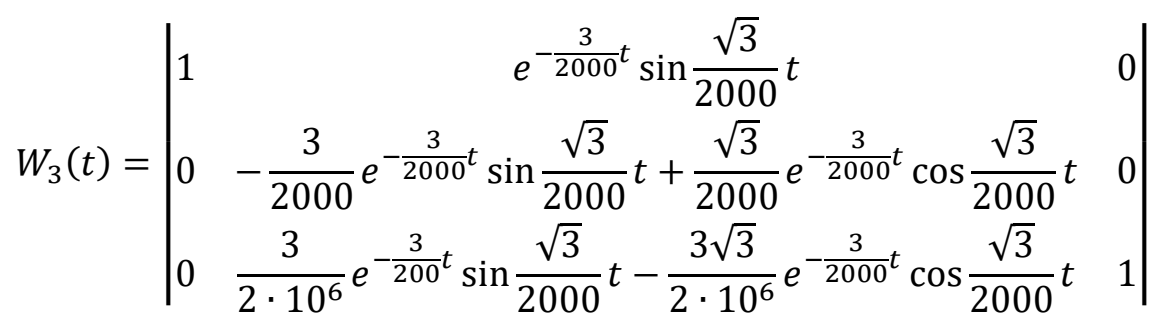

$$
\begin{aligned}
& W_{3}(t)=-\frac{3}{2000} e^{-\frac{3}{2000} t} \sin \frac{\sqrt{3}}{2000} t+\frac{\sqrt{3}}{2000} e^{-\frac{3}{2000} t} \cos \frac{\sqrt{3}}{2000} t . \\
& x_{3} p(t)=x_{31} \int \frac{W_{1}(t)}{W(t)} \cdot f(t) d t+x_{32} \int \frac{W_{2}(t)}{W(t)} \cdot f(t) d t+x_{33} \int \frac{W_{3}(t)}{W(t)} \cdot f(t) d t \\
& x_{3} p(t)=1 \int-\frac{\frac{\sqrt{3}}{2000} e^{-\frac{6}{2000} t}}{-\frac{3 \sqrt{3}}{2 \cdot 10^{9}} e^{-\frac{6}{2000} t}} \cdot \frac{125}{10^{9}} d t \\
& +e^{-\frac{3}{2000} t} \sin \frac{\sqrt{3}}{2000} t \int \frac{\left(\frac{3}{2000} e^{-\frac{3}{2000} t} \cos \frac{\sqrt{3}}{2000} t+\frac{\sqrt{3}}{2000} e^{-\frac{3}{2000} t} \sin \frac{\sqrt{3}}{2000} t\right)}{-\frac{3 \sqrt{3}}{2 \cdot 10^{9}} e^{-\frac{6}{2000} t}} \cdot \frac{125}{10^{9}} d t \\
& +e^{-\frac{3}{2000} t} \cos \frac{\sqrt{3}}{2000} t \int \frac{\left(-\frac{3}{2000} e^{-\frac{3}{2000} t} \sin \frac{\sqrt{3}}{2000} t+\frac{\sqrt{3}}{2000} e^{-\frac{3}{2000} t} \cos \frac{\sqrt{3}}{2000} t\right)}{-\frac{3 \sqrt{3}}{2 \cdot 10^{9}} e^{-\frac{6}{2000} t}} \cdot \frac{125}{10^{9}} d t \\
& x_{3} p(t)=\frac{1}{24} t-\frac{250 \cdot 500}{2000 \sqrt{3}} \sin \frac{\sqrt{3}}{2000} t \cos \frac{\sqrt{3}}{2000} t-2\left(\frac{250 \cdot 500}{2000 \cdot 3}\right) \sin ^{2} \frac{\sqrt{3}}{2000} t \\
& +\frac{250 \cdot 500 \sqrt{3}}{2000 \cdot 3 \cdot 3} \sin \frac{\sqrt{3}}{2000} t \cos \frac{\sqrt{3}}{2000} t
\end{aligned}
$$




$$
\begin{gathered}
+\frac{250 \cdot 500}{2000 \sqrt{3}} \sin \frac{\sqrt{3}}{2000} t \cos \frac{\sqrt{3}}{2000} t-2\left(\frac{250 \cdot 500}{2000 \cdot 3}\right) \cos ^{2} \frac{\sqrt{3}}{2000} t \\
x_{3} p(t)=\frac{1}{24} t-\frac{125}{3}
\end{gathered}
$$

Sehingga solusi umum untuk persamaan (4.a.16) adalah

$$
\begin{aligned}
& x_{3}=x_{3} h(t)+x_{3} p(t) \\
& x_{3}=C_{1}+C_{2} e^{-\frac{3}{2000} t} \sin \frac{\sqrt{3}}{2000} t+C_{3} e^{-\frac{3}{2000} t} \cos \frac{\sqrt{3}}{2000} t+\frac{1}{24} t-\frac{125}{3} .
\end{aligned}
$$

Solusi untuk $x_{2}$ adalah

$$
\begin{aligned}
x_{2}= & C_{1}-\frac{1}{2} C_{2} e^{-\frac{3}{2000} t} \sin \frac{\sqrt{3}}{2000} t+\frac{\sqrt{3}}{2} C_{2} e^{-\frac{3}{2000} t} \cos \frac{\sqrt{3}}{2000} t \\
& -\frac{1}{2} C_{3} e^{-\frac{3}{2000} t} \cos \frac{\sqrt{3}}{2000} t-\frac{\sqrt{3}}{2} C_{3} e^{-\frac{3}{2000} t} \cos \frac{\sqrt{3}}{2000} t+\frac{1}{24} t+\frac{125}{10}
\end{aligned}
$$

Solusi untuk $x_{1}$ adalah

$$
\begin{aligned}
x_{1}= & C_{1}-\frac{1}{2} C_{2} e^{-\frac{3}{2000} t} \sin \frac{\sqrt{3}}{2000} t-\frac{\sqrt{3}}{2} C_{2} e^{-\frac{3}{2000} t} \cos \frac{\sqrt{3}}{2000} t \\
& -\frac{1}{2} C_{3} e^{-\frac{3}{2000} t} \cos \frac{\sqrt{3}}{2000} t+\frac{\sqrt{3}}{2} C_{3} e^{-\frac{3}{2000} t} \cos \frac{\sqrt{3}}{2000} t+\frac{1}{24} t+\frac{125}{3} .
\end{aligned}
$$

Jadi solusi umum dari sistem persamaan diferensial di atas adalah

$$
\begin{aligned}
x_{1}= & C_{1}-\frac{1}{2} C_{2} e^{-\frac{3}{2000} t} \sin \frac{\sqrt{3}}{2000} t-\frac{\sqrt{3}}{2} C_{2} e^{-\frac{3}{2000} t} \cos \frac{\sqrt{3}}{2000} t \\
& -\frac{1}{2} C_{3} e^{-\frac{3}{2000} t} \cos \frac{\sqrt{3}}{2000} t+\frac{\sqrt{3}}{2} C_{3} e^{-\frac{3}{2000} t} \cos \frac{\sqrt{3}}{2000} t+\frac{1}{24} t+\frac{125}{3}, \\
x_{2}= & C_{1}-\frac{1}{2} C_{2} e^{-\frac{3}{2000} t} \sin \frac{\sqrt{3}}{2000} t+\frac{\sqrt{3}}{2} C_{2} e^{-\frac{3}{2000} t} \cos \frac{\sqrt{3}}{2000} t \\
& -\frac{1}{2} C_{3} e^{-\frac{3}{2000} t} \cos \frac{\sqrt{3}}{2000} t-\frac{\sqrt{3}}{2} C_{3} e^{-\frac{3}{2000} t} \cos \frac{\sqrt{3}}{2000} t+\frac{1}{24} t+\frac{125}{10}, \\
x_{3}= & C_{1}+C_{2} e^{-\frac{3}{2000} t} \sin \frac{\sqrt{3}}{2000} t+C_{3} e^{-\frac{3}{2000} t} \cos \frac{\sqrt{3}}{2000} t+\frac{1}{24} t-\frac{125}{3} .
\end{aligned}
$$

Solusi yang diperoleh di atas sudah diperiksa kembali. 


\section{Kesimpulan}

Salah satu teknik yang dapat digunakan dalam menentukan solusi sistem persamaan diferensial linear non homogen orde satu dengan koefisien konstanta adalah dengan mengonstruksinya menjadi persamaan diferensial linear tunggal setelah itu dicari solusi homogen dari persamaan diferensial linear tunggal tersebut dan dicari juga solusi partikularnya dengan metode variasi parameter. Setelah itu menentukan solusi umum dari persamaan diferensial linear tunggal tersebut. Kemudian menentukan solusi dari persamaan-persamaan lain yang membentuk sistem persamaan diferensial tersebut.

\section{Referensi}

[1] Finizio, N dan G. Ladas. 1988. Persamaan Diferensial Biasa dengan Penerapan Modern. Terjemahan oleh Dra. W. Santoso. Jakarta: Erlangga.

[2] Goode, S. W. 1991. An Introductional to Differential Equations and Linear Algebra. New York: Prentice-Hall International, Inc.

[3] Jwamer, K. H. F and Rashid, A. M. 2012. New Technique For Solving System of First Order Linear Differential Equations. Journal Applied Mathematical Sciences, 64: 3177-3183.

[4] Waluya, B. 2006. Buku Ajar Persamaan Diferensial. Semarang: Universitas Negeri Semarang.

[5] MD Johansyah, J Nahar, FH Badruzzaman. 2017. Analisis Turunan dan Integral Fraksional Fungsi Pangkat Tiga dan Fungsi Eksponensial. Jurnal Matematika 16 (2). 